\title{
Correction: Abdulle, A.E., et al. Hydrogen Sulfide: A Therapeutic Option in Systemic Sclerosis. Int. J. Mol. Sci. 2018, 19, 4121
}

\author{
Amaal Eman Abdulle $1, * \mathbb{C}$, Harry van Goor ${ }^{2,+} \mathbb{C}$ and Douwe J. Mulder ${ }^{1,+}$ \\ 1 Department of Internal Medicine, Division Vascular Medicine, University of Groningen, University Medical \\ Centre Groningen, Hanzeplein 1, 9713 GZ Groningen, The Netherlands; d.j.mulder@umcg.nl \\ 2 Department of Pathology and Medical Biology, Section Pathology, University of Groningen, University \\ Medical Centre Groningen, Hanzeplein 1, 9713 GZ Groningen, The Netherlands; h.van.goor@umcg.nl \\ * Correspondence: a.eman.abdulle@umcg.nl; Tel.: +31-50-361-3400; Fax: +31-50-361-3312 \\ + These authors contributed equally to this work.
}

The authors wish to make the following correction to this paper [1].

Reference [8] refers to the wrong article. The correct reference [2] should be:

Abdulle, A.E.; Diercks, G.F.H.; Feelisch, M.; Mulder, D.J.; van Goor, H. The Role of Oxidative Stress in the Development of Systemic Sclerosis Related Vasculopathy. Front. Physiol. 2018, 9, 1-15, doi:10.3389/fphys.2018.01177.

The authors would like to apologize for any inconvenience caused to the readers by these changes.

\section{References}

1. Abdulle, A.E.; van Goor, H.; Mulder, D.J. Hydrogen Sulfide: A Therapeutic Option in Systemic Sclerosis. Int. J. Mol. Sci. 2018, 19, 4121. [CrossRef] [PubMed]

2. Abdulle, A.E.; Diercks, G.F.H.; Feelisch, M.; Mulder, D.J.; van Goor, H. The Role of Oxidative Stress in the Development of Systemic Sclerosis Related Vasculopathy. Front. Physiol. 2018, 9, 1-15. [CrossRef] [PubMed]



(C) 2019 by the authors. Licensee MDPI, Basel, Switzerland. This article is an open access article distributed under the terms and conditions of the Creative Commons Attribution (CC BY) license (http://creativecommons.org/licenses/by/4.0/). 